\title{
Projected Impacts of Bioenergy-Demand-Induced Land Use and Cover Changes on Regional Climate in Central Europe
}

\author{
Fang Yin, ${ }^{1,2}$ Yihui Xiong, ${ }^{3}$ Li Jiang, ${ }^{4}$ and Zhiguo Pang ${ }^{5,6}$ \\ ${ }^{1}$ Institute of Geographic Sciences and Natural Resources Research, Chinese Academy of Sciences, No. 11A, Datun Road, Anwai, \\ Beijing 100101, China \\ ${ }^{2}$ Center for Chinese Agricultural Policy, Chinese Academy of Sciences, Beijing 100101, China \\ ${ }^{3}$ Faculty of Information Engineering, China University of Geosciences, No. 388, Lumo Road, Wuhan 430074, China \\ ${ }^{4}$ School of Economics, Renmin University of China, Beijing 100872, China \\ ${ }^{5}$ State Key Laboratory of Simulation and Regulation of Water Cycle in River Basin, Beijing 100048, China \\ ${ }^{6}$ China Institute of Water Resources and Hydropower Research, Beijing 100048, China
}

Correspondence should be addressed to Fang Yin; yinf.dls@gmail.com

Received 18 July 2013; Revised 9 September 2013; Accepted 17 September 2013

Academic Editor: Xiangzheng Deng

Copyright (C) 2013 Fang Yin et al. This is an open access article distributed under the Creative Commons Attribution License, which permits unrestricted use, distribution, and reproduction in any medium, provided the original work is properly cited.

\begin{abstract}
Energy shortfalls are becoming more and more serious all over the world, and worldwide governments have tried to promote the development of biofuels in order to mitigate the climatic impacts of massive fossil fuel consumption. Since the land is the main input factor of the bioenergy production, the development of biofuels will inevitably lead to change of the land use structure and allocation and thereby affect the climate system. With Central Europe as the study area, this study explored the impacts of land use/land cover change (LUCC) on climate under the influence of demand of bioenergy production for land resources. First, the land use structure from 2010 to 2050 is simulated with the Agriculture and Land Use model in MiniCam. The result indicates that the main conversion will be mainly from grassland and forest to cropland and from cropland to grassland. Then the Dynamics of Land System model was used to spatially simulate the LUCC in the future. The impacts of LUCC on the climate were analyzed on the basis of simulation with the Weather Research and Forecasting (WRF) model. The climate change will be characterized by the increase of latent heat flux and temperature and the decrease of precipitation.
\end{abstract}

\section{Introduction}

Energy shortfalls have been increasingly serious all over the world; meanwhile, the renewable energy is rapidly developing but has not become a significant source of energy yet [1]. Since the 1990s, the United States, high-energy-consumption countries in Europe, and the agricultural products trading countries such as Brazil have begun to develop the renewable bioenergy [2]. As the main type of the renewables, the worldwide governments are also promoting its development in order to mitigate the climatic effects of the consumption of massive fossil fuel. At the same time, it is becoming a scientific research hotspot in recent decades. Some previous researches on the effectiveness of bioenergy have estimated the potential impacts of the development of renewable energy according to the change of greenhouse gas (GHG) emission due to land use/land cover change (LUCC) and by means of life cycle analysis (LCA) [3]. LUCC has great impacts on GHGs, and it also modifies the surface energy and water balance $[4,5]$ through influencing the near-surface temperature and precipitation. Besides, it serves as an additional driving force of the climate change at the global [6-9] and regional [10-12] scales. This study mainly focused on the effects of bioenergy development on LUCC, which influences the biogeophysical processes of the land surface and subsequently impacts the climate change.

The bioenergy has showed high potential in coping with the worldwide energy crisis and increasingly serious environmental problems since it is famous for being renewable, biodegradable, nontoxic, and environmentally friendly [13]. Most researchers have studied the impacts of the growth 
and production of the bioenergy with the GBEP common methodological framework for GHG lifecycle analysis of bioenergy [14]. An additional 15\% of greenhouse emission results from the land use change, especially the change linked to deforestation caused by the expansion of agricultural land. Croplands have higher albedo than that of forests, and there is lower absorption of solar radiation over deforested areas [15]. Due to bioenergy production needing cultivated land or land $[16,17]$, it changes land use structure [18], affecting the carbon sinks at the same time and then influences climate change, including the change of temperature, precipitation, and evaporation. What is more is that the Global Bioenergy Partnership [19] has reported that specific significant methodological uncertainties and methodological choices that can significantly affect the indicator values are related to indirect land use change and base year to measure the LUCC.

Nevertheless, most of studies indicate there may be some (potential) surplus of agricultural land in the EU in the near future, while the cropland in Central Europe has shown a downward trend since 1970 [20]. The size of this surplus, however, depends on a large number of factors. The general conclusion is that the future availability of land for bioenergy production will be largely determined by the agricultural policy and market development. Another general conclusion is that the above-mentioned studies focused on the aggregated amount, which only provide limited insight into developments at the regional scale. A number of studies provide important information on the environmental effects of bioenergy production at the plot scale. However, these studies failed to capture the effects of bioenergy production at the landscape scale [21].

The climatic impacts of LUCC through influencing the terrestrial biogeophysical processes have attracted more and more attention in the current scientific domain [22-24]. LUCC can alter the convective rainfall and other regional weather patterns such as the surface flux of moisture and sensible and latent heat fluxes [25]. It is very difficult to summarize the effects of land cover change on the climate since the climatic impacts of different biogeophysical effects may offset each other [26]. Besides, in comparison to the impacts of land cover change at the global or annual scales, the impacts of land cover change at the regional scale have not been well represented in the annual or global average statistics since it may often show opposite signs [27]. In fact, the coarse resolution of the Global Circulation models (GCMs) seriously limits their capability to capture the mesoscale features that play a pivotal role in regional dynamics [12]. By comparison, the Regional Circulation models (RCMs) are more suitable for the studies at the regional scale.

Currently, an increasing number of researchers have studied the effects of LUCC on the regional climate with the dynamic downscaling $[20,28,29]$, with different original data, conversion technologies, and applications. The expansion of agricultural land at the middle latitudes leads to the decrease of the range of daily average temperature in many areas [30]. Many scholars studied effects of LUCC on the regional climate with the RCMs inversion, while the parameterization of the process is not completely targeted on the bioenergy in some researches. This study mainly aims to clarify how the production of bioenergy influences LUCC and its impacts on the climate change. This study firstly reviewed how the development of bioenergy in Central Europe influences land use such as conversion from grasslands and forest lands to cultivated lands. Then the impacts of LUCC on the temperature, precipitation, and heat balance were detected and analyzed on the basis of simulation with the Weather Research and Forecasting (WRF) model.

\section{Methods}

This study explored the LUCC under the influence of demand of bioenergy production for land resources with a multiscale and multimodel approach and simulated its effects on the climate change. Firstly, the land use structure from 2010 to 2050 was simulated with the Agriculture and Land Use model (AgLU) in GCAM. The AgLU model is a top-down economic model with enough structures to simulate the global land use change and the consequent carbon emission over one century [31]. These simulations were implemented with and without a carbon policy which was represented with a positive carbon price. Changes in the carbon price create incentives for commercial production of biomass, which affects the distribution of other land types and subsequently influences the carbon emission from land use change. Commercial production of biomass provides a link between the agricultural and energy systems. In this study, the main driving forces of land use change were analyzed, including the economic growth, income growth, demand for food growth, population growth, climate change, and especially demand for bioenergy production. The core of the LUCC lies in the distribution mechanism between the cropland, grassland, forest land, and unused land and the maximization of regional economic profit.

Demand equation (1) for each of the crops, processed crops, and animal products is expressed with the unit of total calories demanded per year as follows:

$$
\mathrm{CDR}_{i, l, m}=A_{i, l} \cdot\left(\frac{P_{i, l, m}}{P_{i, l, m=\text { baseyear }}}\right)^{\alpha_{j i}} \cdot Y_{i, l, m}^{\beta_{j i}} \cdot N_{l, m} \cdot C_{i, l, m},
$$

where $\mathrm{CDR}_{i, l, m}$ is the demand for calories (total calories demanded per year in a region at time $t$ ), $i$ can be crops, processed crops, or animal products, $l$ is a region index, $m$ is the point in time of the calculation, $A_{i, l}$ is a scaling coefficient (unitless) to calibrate the price and income feedback terms in the base year, $P_{i, l, m}$ is the market price of the commodity (\$/calories consumed per person per day), $\alpha_{j i}$ is the price elasticity, $Y_{i, l, m}$ is per capita income index $\{\$ \mathrm{GDP} /$ population/(\$ $\mathrm{GDP} /$ population in base year) $\}, \beta_{j i}$ is the income elasticity for the calories demanded which implies it may differ from income elasticity in the demand equation for transportation, industry, or buildings $\left(r_{y k l m}\right), N_{l, m}$ is the total population by region (which differs from the population index, the ratio of the regional population at time $t$ divided by the regional population in the base year, in the demand equation for energy services in the transportation and building sector), and $C_{i, l, m}$ is calories consumed per person per day (multiplied by 365 to get yearly consumption). 
Equation (2) is to compute demand for two types of forest products, industrial wood and fuel wood:

$$
\mathrm{WDR}_{i, l, m}=A_{i, l} \cdot\left(\frac{P_{i, l, m}}{P_{i, l, m=\text { baseyear }}}\right)^{\alpha_{j i}} \cdot Y_{i, l, m}^{\beta_{j i}} \cdot N_{l, m},
$$

where $\mathrm{WDR}_{i, l, m}$ is industrial wood and fuel wood in cubic meters demanded.

Selection of land use is based on maximizing economic return at each location. Profit per hectare is equal to revenue (yield per hectare times price received) minus production cost (yield per hectare times nonland cost per unit of output). This relationship is shown in (3), where $i$ is an index for land use type, $l$ is the region index, and $p$ is an index for geographical location within a region:

$$
\pi r_{i, l, m, p}=y_{i, l, m, p} \cdot\left(P_{i, l, m}-G_{i, l, m}\right),
$$

where $\pi r_{i, l, m, p}$ is the economic return of the land as a profit rate ( $\$ /$ ha-yr), $P_{i, l, m}$ is the market price for the product produced by land use $i$ (units $\$$ /yield units: calories or $\mathrm{m}^{3}$ ), $G_{i, l, m}$ is the nonland cost per unit of output in land use (units are $\$$ /yield units: calories or $\left.\mathrm{m}^{3}\right) . \widetilde{P}_{i, l, m}$ is the forward price for forest products which is the time lag between planting and harvest.

Consider

$$
\pi r_{i, l, m, p}=\frac{r}{(1+r)^{45}-1} \cdot y_{i, l, m, p} \cdot\left(\widetilde{P}_{i, l, m}-G_{i, l, m}\right),
$$

where $r$ is the interest rate ( $\$ / \$$, that is, unitless).

With specific assumptions on the functional form of the yield distribution, the share of land allocated to use $i$ is given by a logit share equation:

$$
S_{i, l, m}=\frac{\bar{\pi} r_{i, l, m}^{1 / \lambda}}{\sum_{p} \bar{\pi} r_{i, l, m, p}^{1 / \lambda}}
$$

where $\lambda$ is a positive parameter that determines the rate that land shares change in response to a change in profit rate.

Land use for a specific purpose is calculated based on this logit-based share of total land:

$$
\text { land } \text { use }_{i, l, m}=S_{i, l, m} \cdot \text { Total land } \text {. }
$$

Then the Dynamics of Land System (DLS) model was used to spatially simulate the LUCC through identifying conversions between cropland and other land cover types during the period of 2010-2050. DLS, a good model for allocation of land use pattern depending on the specific demand, is a collection of programs that simulates the changes in the land use pattern through conducting scenario analysis of land use change in the study area [32, 33]. Firstly, the effects of geophysical conditions and socio-economic environment on the spatial patterns of cropland area were explored, and the predominant driving factors on the spatial pattern of cropland were identified. Secondly, the changing trend of the predominant factors influencing spatial patterns of cropland was predicted through considering the historical characteristics and current status at the regional scale.
TABLE 1: Physical process and parameterization scheme.

\begin{tabular}{lc}
\hline Physical process & Alternative parameterization scheme \\
\hline $\begin{array}{l}\text { Lateral boundary } \\
\text { forcing data }\end{array}$ & Kessler, NCEP/FNL dataset, Ferrier \\
Cumulus & New Kain-Fritsch, Grell-Devenyi set, \\
Shortwave radiation & Betts-miller-Janjic \\
Longwave radiation & RRTM, CAM scheme, GFDL \\
Boundary layer & MRF, MYJ, YSU \\
Land surface schemes & STD, RUC, Noah \\
\hline
\end{tabular}

Thirdly, a proper scenario was selected to predict the balance between the supply and demand of land resources. The net changes of cropland area, which are constrained by the supply and demand of land among various land-consuming sectors, were allocated into each pixel according to the land use structure. Finally, the cropland area was spatially allocated at $30 \mathrm{~km} \times 30 \mathrm{~km}$ grid scale, and the spatial pattern was finally generated.

Finally, the climate change was simulated with the Weather Research and Forecasting (WRF) model in order to assess the impacts of LUCC on the regional climate. The WRF model, a regional climate model for higher regional projection, is a next-generation mesoscale numerical weather prediction system designed to serve both atmospheric research and operational forecasting needs. It is featured by two dynamical cores, a data assimilation system and a software architecture that allows the parallel computation and system extensibility. The model serves a wide range of meteorological applications across scales ranging from meters to thousands of kilometers. The model version 3.5 which was developed by the National Center for Atmospheric Research (NCAR) includes three land surface schemes in Table 1: the simple soil thermal diffusion (STD) scheme, the Noah scheme, and the Rapid Update Cycle (RUC) scheme [34]. The lateral boundary forcing data came from the NCEP/FN dataset and was updated every 6 hours. In the parameterization scheme of the physical process in the model, the cumulus parameterization scheme adopted the Grell-Devenyi ensemble scheme, the boundary layer process scheme was YSU, and the shortwave radiation scheme was the CAM scheme, while the land surface process scheme was Noah land surface model. The boundary buffer was set to be 4 layers of grid points, and the boundary conditions adopted the relaxation scheme. The time interval of the model integration was set to be 5 minutes, and that of the radiation process and cumulus convection was half an hour and 5 minutes, respectively. There were 27 layers in the vertical direction, and the atmospheric pressure at the top layer was $50 \mathrm{hPa}$.

The WRF model was used to simulate the climate change from 2040-2050 with the first year as spin up. There was a set of tests which was used to simulate the climate of 2010 to validate the method. A 10 -year simulation ensured that we would see how surface climate changes with respect to land cover change, while we found that a 1-year spin up was enough to initialize the soil moisture. The simulation area was 
centered at $50^{\circ} \mathrm{N}$ and $10^{\circ} \mathrm{E}$ and was projected on a Lambert conformal grid covering almost the whole of Germany; the area covers 32 and 21 grid points in the longitudinal and latitudinal directions, respectively. The spatial resolution of the model is $30 \mathrm{~km} \times 30 \mathrm{~km}$; the main topographic features of the simulation area are captured at this fine resolution.

\section{Data Processing}

3.1. Biofuel in Europe. The Organization for Economic Cooperation and Development (OECD) gives out the statistics of the contribution of renewables to energy supply (Figure 1), which showed an obviously increasing trend during 19902010.

There has been substantial growth of bioenergy in the EU over the past decades, especially the bioenergy for the modern energy carriers' electricity and the transport sector. The proportions of renewable energy produced in the EU in 2005 were as follows: $66.1 \%$ from biomass, $22.2 \%$ from hydropower, 5.5\% from wind power, 5.5\% from geothermal energy, and $0.7 \%$ from solar power. In general, bioenergy plays an essential role in the European ambition to increase the share of renewable and domestic energy. During 19902010 , the thermal power increased by approximately $2 \%$ per year, bioelectricity increased by approximately $9 \%$ per year, while the bioenergy production increased about eight times (with an increasing rate over $20 \%$ per year).

The contribution of bioenergy to the energy supply in the EU in 1990 was a bit less than 2000 PJ, accounting for two-thirds of the total renewable energy production or $4 \%$ of the total energy supply in the EU. There will be a significant increase of the market share of bioenergy in energy supply in the EU, with the aim of reaching $1 \%$ on average (it has doubled in two years). In addition, there is significant difference in the market share of bioenergy in energy supply among different countries in the EU; for example, that of Germany (3.8\%) and Sweden (2.2\%) has achieved the reference value.

In order to reach the ambitious target of a $20 \%$ share of energy from renewable sources in the overall energy consumption amount, the EU plans to make efforts on the electricity, heating and cooling sectors, and biofuels. In the transportation industry, which is almost exclusively dependent on oil, the EU commission hopes that the share of biofuels in the overall fuel consumption will have reached $10 \%$ by 2020 . So it was assumed that the share of biofuels may achieve $20 \%$ by 2050 according to this trend in this study.

3.2. History of LUCC and Climate Change. With the rapid development of bioenergy, the land use pattern in Europe has also gradually changed. The land use change caused by the development of bioenergy is mainly represented by the conversion from grassland and forest to cropland. According to OECD statistics, about $27.5 \%$ of land in Europe is arable and permanent cropland, and permanent grassland accounts for only $16.2 \%$, while the forest accounts for $32.4 \%$. We also found in the History Today (2001) that the cropland in Central Europe increased from 41.9 Mha in 1900 to 56.9 Mha in 1960, and since then it fell to 46.7 Mha in 2005 with the

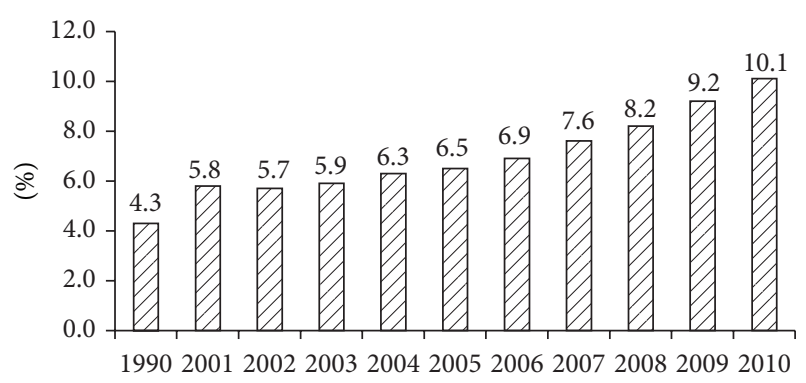

FIgure 1: Percentage of renewables in energy supply in OECD Europe, 1900-2010. Source: Factbook 2012 - ISSN - OECD 2012.

growth rates per year of $0.41 \%$ from 1900 to 1950 and $-0.03 \%$ between 1950 and 2000 .

The annual average temperature has been $10^{\circ} \mathrm{C}$, and the annual precipitation has ranged from $700 \mathrm{~mm}$ to $1000 \mathrm{~mm}$ in Central Europe during 1900 to 2010. According to the statistics of temperature and precipitation data in the past [35], the temperature showed an obvious increasing trend with the increment of $1.3^{\circ} \mathrm{C}$ (Figure 2(a)), and there is also an increase in the coefficient of variation, while there is no obvious changing trend of the precipitation with little decrease of $15 \mathrm{~mm}$ (Figure 2(b)). The climate in the study area is characterized by the peaks and valleys of temperature and precipitation appearing during the same period. The minimum values of temperature and precipitation both appear in January, reaching about $2^{\circ} \mathrm{C}$ and $80 \mathrm{~mm}$, respectively, while their maximum values generally appear in July, reaching about $18^{\circ} \mathrm{C}$ and $100 \mathrm{~mm}$, respectively.

\section{Results}

4.1. Land Use Change. In Central Europe, the main land use type is cropland. At the beginning of the 21st century, cropland accounted for about $67 \%$ of the total land area and forest accounted for $17 \%$, while grassland only accounted for $10 \%$. The cropland is mainly distributed in the northern part of the study area, while the forest is generally located in the southern part where there are mountainous areas. The current land use situation and the dominant conversion types are shown in Figure 3. Based on the GCAM model, the trend of land use change in the next 40 years was simulated. The result indicated that it is mainly characterized by the conversion from cropland to other land use types in the northwest part, while the conversion from forest into cropland dominates the southern part. Nearly $30 \%$ of the grassland and $2.7 \%$ of the forest land will be converted into cropland in the study area in the future. However, in the process of the development of biomass energy, not only the other land use types will be converted into cropland but also some cropland will be converted into grassland, while on the whole, the cropland area in Central Europe will increase to some extent. Part of grasslands, forests, and some other land will be converted into cropland, which will cause the change of land use and eventually influence the climate change in Europe (Table 2). 


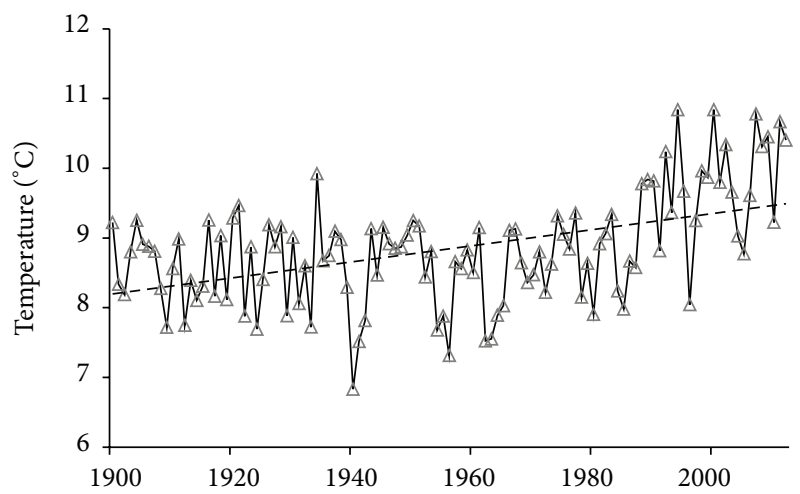

(a)

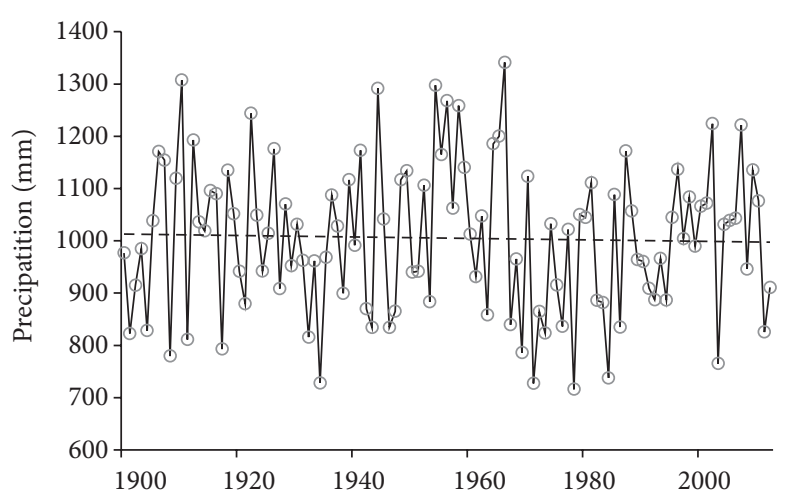

(b)

Figure 2: (a) Annual temperature in Central Europe, 1900-2010. (b) Annual precipitation in Central Europe, 1900-2010.

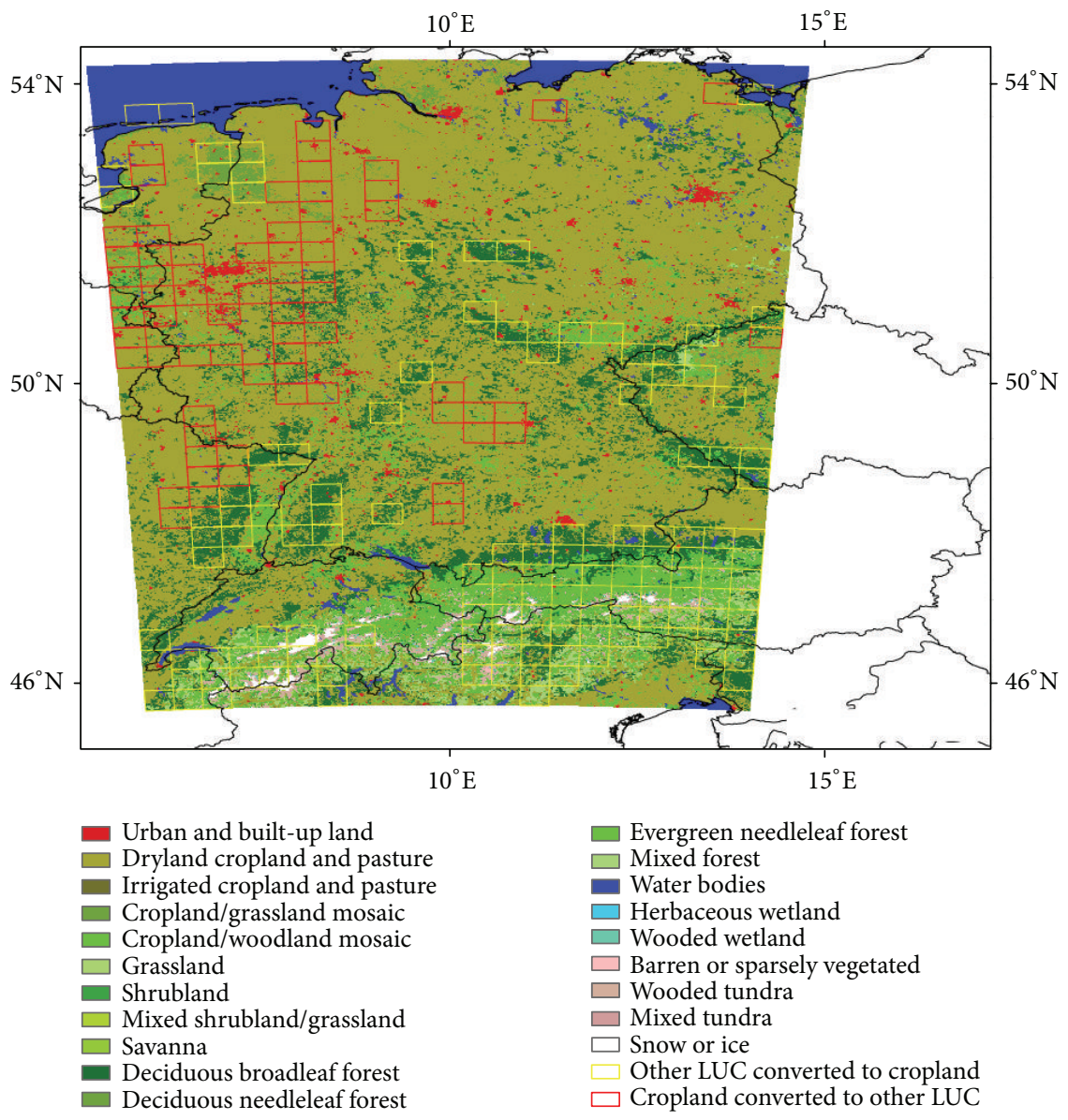

FIGURE 3: Major land use conversion in Central Europe, 2010-2050.

TABLE 2: Transition matrix of LUCC with grid count and percent in Central Europe during 2010 to 2050.

\begin{tabular}{|c|c|c|c|c|c|}
\hline & Cropland & Grassland & Forest & Others & Total \\
\hline Cropland & $444(97.8 \%)$ & $10(2.2 \%)$ & 0 & 0 & $454(67.6 \%)$ \\
\hline Grassland & $20(29.4 \%)$ & $48(70.6 \%)$ & 0 & 0 & $68(10 \%)$ \\
\hline Forest & $13(2.7 \%)$ & 0 & $101(88.6 \%)$ & 0 & $114(17 \%)$ \\
\hline Others & 0 & 0 & 0 & $36(100 \%)$ & $36(5.4 \%)$ \\
\hline Total & $477(71 \%)$ & $58(8.6 \%)$ & $101(15 \%)$ & $36(5.4 \%)$ & 672 \\
\hline
\end{tabular}




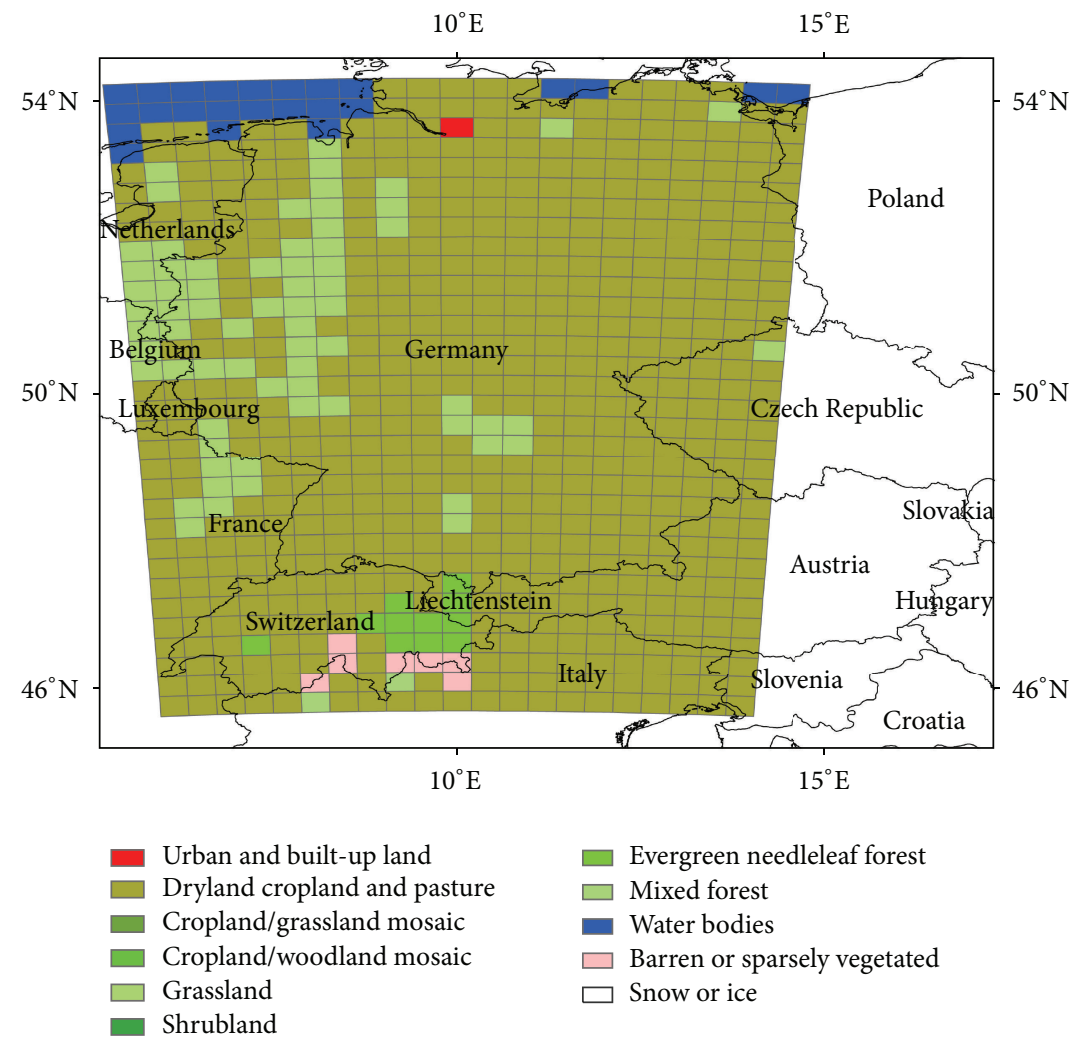

FIGURE 4: Projected LUC situation of Central Europe in 2050.

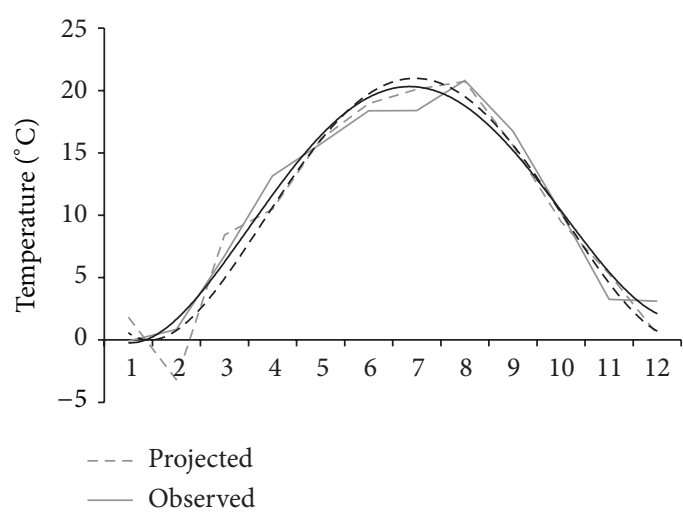

(a)

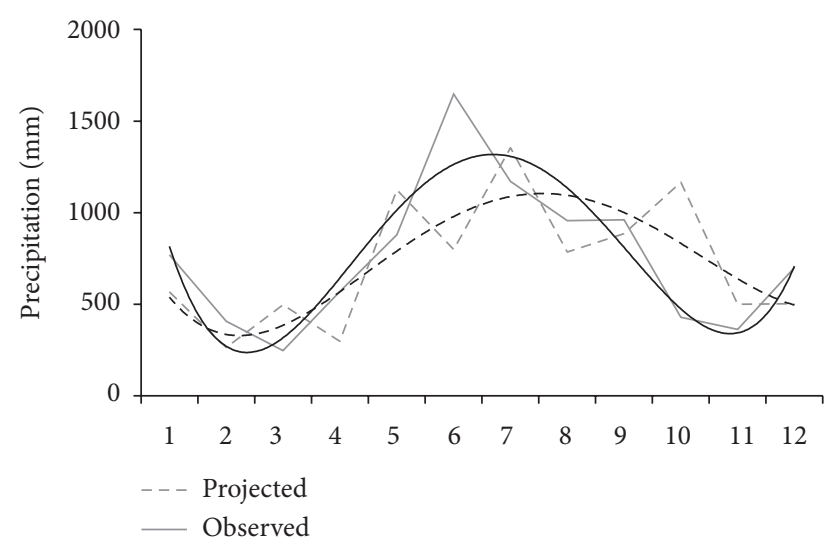

(b)

FIGURE 5: (a) Difference between observed and projected surface temperature in Central Europe in 2010. (b) Difference between observed and projected precipitation in Central Europe in 2010.

The trend of land use change in the next 40 years was obtained according to the simulation result with DLS, which was presented with the red and yellow boxes as main conversion from cropland and conversion into cropland, respectively (Figure 3). The result indicated that there will be some obvious land use change in the study area. In the northwestern part, a lot of cropland will be converted into other land use types, while in the southern part, some forests and grasslands will be converted into cropland. The projected land use in 2050 will be presented in Figure 4, and obviously cropland has increased and forest has decreased.

4.2. Climate Change in 2010-2050. To validate the precision of simulation result with the WRF model, the simulation data of year 2010 were compared with the observation. The comparison result indicated that the accuracy of the projection of temperature (Figure 5(a)) was higher than that of precipitation (Figure 5(b)). In spring and winter from 


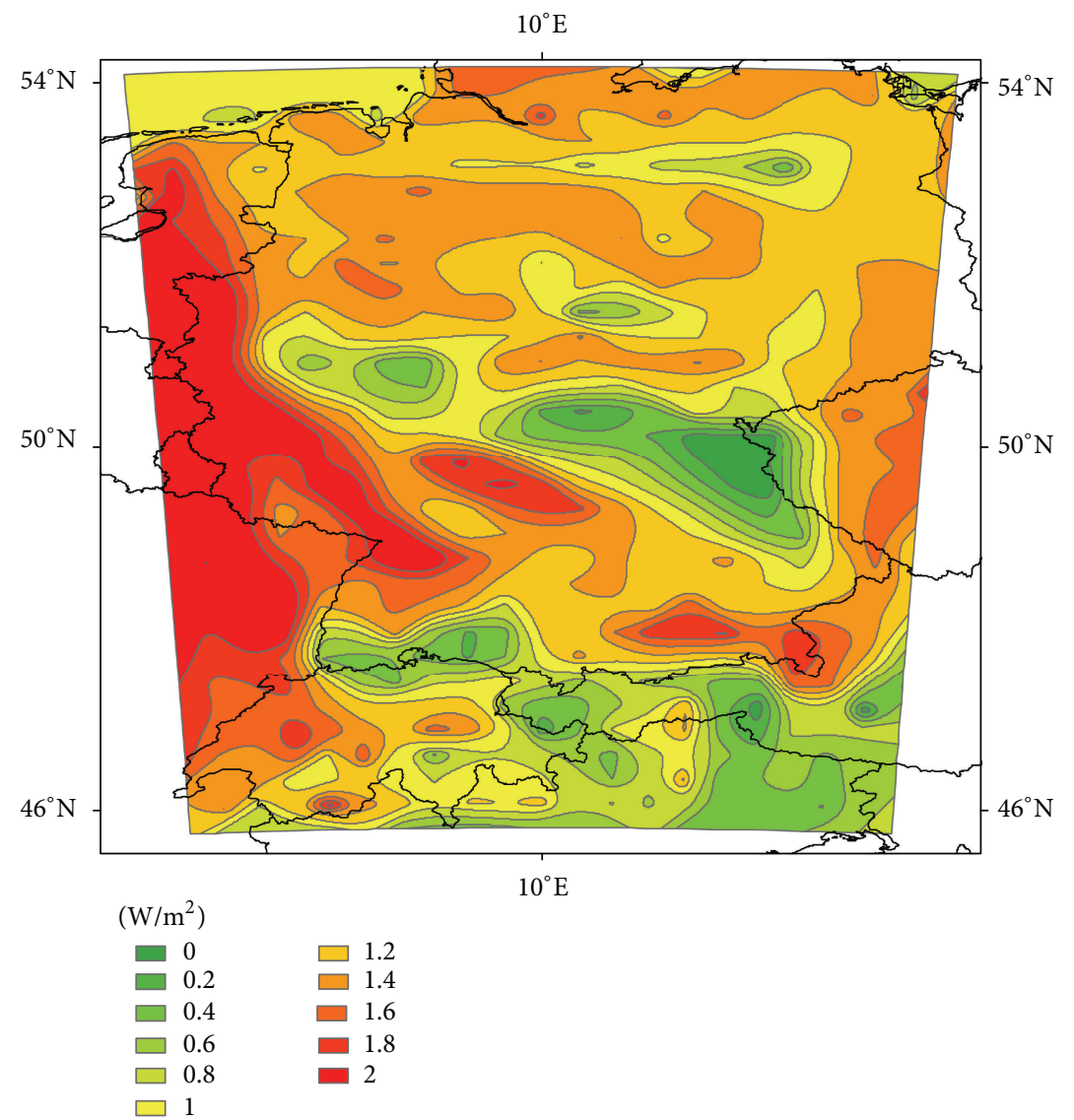

Figure 6: Annual changes of projected latent heat flux in Central Europe, 2040-2050.

January to April and November to December, simulated temperature is a little far away from the observed one, and the temperature difference of winter is higher than other seasons, and the simulation values were closer to the observations in the summer and autumn. The simulation result indicated that the simulated temperature from January to April and from November to December was a little far away from the observed one. Besides, the difference between the simulated and observed temperature in the winter is greater than that in other seasons, while the simulated and observed ones in the summer and autumn are more consistent. On the whole, the trends of the simulated and observed temperature were consistent, both of which show an increasing trend from January and February, reaching the peak in August and then show a decreasing trend. The comparison between the simulated and observed precipitation indicated that there is significant difference between simulated and observed values. According to the observation data, the precipitation is the lowest in March, and the peak occurs in June, reaching about $1600 \mathrm{~mm}$. Then it declines to less than $500 \mathrm{~mm}$ in November. By comparison, the simulated precipitation fluctuates over the year, with higher values occurring in the summer and autumn.

As is shown in Table 3, the minimum temperature in 2050 appears in December, reaching $2.56^{\circ} \mathrm{C}$, while the maximum temperature appears in July, reaching $21.73^{\circ} \mathrm{C}$. The average temperature is $12.38^{\circ} \mathrm{C}$, while the counterpart in 2010 is $11.19^{\circ} \mathrm{C}$. The minimum and maximum of precipitation occur in November and July, reaching $80 \mathrm{~mm}$ and $463 \mathrm{~mm}$, respectively. In terms of cumulative precipitation, there is $3346 \mathrm{~mm}$ in 2050 and $5749 \mathrm{~mm}$ in 2010. By comparison, the heat flux is much more stable all year round and so is the latent heat. During 2040-2050, the temperature shows an increasing trend, with an increment of $0.2^{\circ} \mathrm{C}$, while the precipitation will decrease by $65 \mathrm{~mm}$ per month. The latent heat shows an increasing trend (Figure 6), with an increasing rate of $0.4 \%$ per year, while the heat flux stays at a stable status.

\section{Conclusions and Discussions}

5.1. Conclusions. The result of this study indicated that the increase of production of bioenergy in Central Europe would lead to more demand for cropland in the southern part of the study area. The increasing demand of bioenergy for land resources would lead to LUCC which will change the land surface and subsequently influence the future climate. The LUCC in the future was simulated with DLS, and the impacts of LUCC on the climate were analyzed on the basis of projection with the WRF model. The simulation result indicated that the region land use change is mainly characterized by the conversion from forest and grassland to farmland by 2050 , which makes the latent heat flux and 
TABLE 3: Monthly projected values of climatic factors in Central Europe in 2050.

\begin{tabular}{|c|c|c|c|c|c|c|c|}
\hline Simulation & Unit & Jan & Feb & Mar & Apr & May & Jun \\
\hline Temperature & ${ }^{\circ} \mathrm{C}$ & 5.94 & 5.79 & 10.0 & 13.6 & 17.3 & 21.4 \\
\hline Latent heat flux & $\mathrm{W} / \mathrm{m}^{2}$ & 124 & 98.9 & 101 & 103 & 124 & 120 \\
\hline Precipitation & $\mathrm{mm}$ & 215 & 188 & 255 & 316 & 332 & 396 \\
\hline Heat flux & $\mathrm{W} / \mathrm{m}^{2}$ & 259 & 259 & 263 & 267 & 270 & 274 \\
\hline Simulation & Unit & Jul & Aug & Sep & Oct & Nov & Dec \\
\hline Temperature & ${ }^{\circ} \mathrm{C}$ & 21.7 & 18.7 & 13.7 & 9.17 & 8.72 & 2.56 \\
\hline Latent heat flux & $\mathrm{W} / \mathrm{m}^{2}$ & 116 & 104 & 116 & 80.7 & 121 & 80.9 \\
\hline Precipitation & $\mathrm{mm}$ & 468 & 443 & 336 & 181 & 80.6 & 128 \\
\hline Heat flux & $\mathrm{W} / \mathrm{m}^{2}$ & 275 & 272 & 267 & 262 & 262 & 256 \\
\hline
\end{tabular}

temperature show an increasing trend, while precipitation will show a decreasing trend.

5.2. Discussions. This study explored the impacts of LUCC on climate change at the landscape scale under the influence of demand of bioenergy production for land resources. The results indicated that expansion of cropland is mainly due to the human demand for bioenergy, which is consistent with the current energy strategies and policies $[36,37]$. Once the Common Agricultural Policy (CAP) is implemented, there may be some reform and rationalization in agriculture due to the change of current land use, productivity of agricultural land, and the expected major transitions of the agricultural sector in Central Europe $[38,39]$, which may provide some opportunities for the alternative crops. Besides, the production of bioenergy may also increase the intensity of land use through improving the technology and education [40]. The spatial pattern of production of bioenergy represented with the ecological indicators of farmland quality [41] will be essential to the assessment of the climate effects of the development of bioenergy as well. Conversion from forest to cropland or pasture reduces the aerodynamic roughness of the landscape and decreases both the capture of precipitation on the canopy and the root extraction of soil moisture; these changes tend to decrease evaporation and hence reduce the fluxes of moisture and latent heat from the surface to the atmosphere, which acts to increase the temperature near the surface. In addition, the land use change is related to not only human activities but also the natural processes, which have not been taken into consideration in this study. What is more is that the earth is a complex system that involves various factors that directly influence the LUCC and subsequently influence the climate change as well as various factors that directly influence the climate change. Therefore, there are still some uncertainties in the result of this study, and it is necessary to carry out further researches on the sensitivity and uncertainty of the impacts of LUCC on the climate change.

\section{Conflict of Interests}

The authors declare that there is no conflict of interests regarding the publication of this paper.

\section{Acknowledgments}

This research was supported by the National Key Programme for Developing Basic Science in China (no. 2010CB950900), the Key Project funded by the Chinese Academy of Sciences (no. KZZD-EW-08), and the External Cooperation Program of the Chinese Academy of Sciences (no. GJHZ1312).

\section{References}

[1] L. Zhang, Z. Yang, B. Chen, and G. Chen, "Rural energy in China: pattern and policy," Renewable Energy, vol. 34, no. 12, pp. 2813-2823, 2009.

[2] M. El-Ashry, Renewables 2010 Global Status Report, REN21 Secretariat, Copyright Deutsche (GTZ) GmbH, Paris, France, 2010.

[3] S. Chen, B. Chen, and D. Song, "Life-cycle energy production and emissions mitigation by comprehensive biogas-digestate utilization," Bioresource Technology, vol. 114, pp. 357-364, 2012.

[4] R. M. Bright, F. Cherubini, and A. H. Strømman, "Climate impacts of bioenergy: inclusion of carbon cycle and albedo dynamics in life cycle impact assessment," Environmental Impact Assessment Review, vol. 37, pp. 2-11, 2012.

[5] X. Deng, C. Zhao, and H. Yan, "Systematic modeling of impacts of land use and land cover changes on regional climate: a review," Advances in Meteorology, vol. 2013, Article ID 317678, 11 pages, 2013.

[6] S. Sitch, V. Brovkin, W. von Bloh, D. van Vuuren, B. Eickhout, and A. Ganopolski, "Impacts of future land cover changes on atmospheric $\mathrm{CO}_{2}$ and climate," Global Biogeochemical Cycles, vol. 19, no. 2, Article ID GB2013, pp. 1-15, 2005.

[7] J. A. Foley, R. DeFries, G. P. Asner et al., "Global consequences of land use," Science, vol. 309, no. 5734, pp. 570-574, 2005.

[8] P. K. Snyder, C. Delire, and J. A. Foley, "Evaluating the influence of different vegetation biomes on the global climate," Climate Dynamics, vol. 23, no. 3-4, pp. 279-302, 2004.

[9] S. M. Sterling, P. Haff, R. Jackson, and W. Schlesinger, "The impact of anthropogenic global land cover transformation on the land-atmosphere fluxes of the water and carbon cycles," Duke University, 2005.

[10] M. Schaeffer, B. Eickhout, M. Hoogwijk et al., " $\mathrm{CO}_{2}$ and albedo climate impacts of extratropical carbon and biomass plantations," Global Biogeochemical Cycles, vol. 20, no. 2, Article ID GB2020, 2006. 
[11] M. Georgescu, D. B. Lobell, and C. B. Field, "Potential impact of U.S. biofuels on regional climate," Geophysical Research Letters, vol. 36, no. 21, Article ID L21806, 2009.

[12] A. J. Pitman, A. Arneth, and L. Ganzeveld, "Regionalizing global climate models," International Journal of Climatology, vol. 32, no. 3, pp. 321-337, 2012.

[13] X. Deng, J. Han, and F. Yin, "Net energy, $\mathrm{CO}_{2}$ emission and land-based cost-benefit analyses of jatropha biodiesel: a case study of the Panzhihua region of Sichuan Province in China," Energies, vol. 5, no. 7, pp. 2150-2164, 2012.

[14] Y. Cao and A. Pawłowski, "Life cycle assessment of two emerging sewage sludge-to-energy systems: evaluating energy and greenhouse gas emissions implications," Bioresource Technology, vol. 127, pp. 81-91, 2013.

[15] V. K. Arora and A. Montenegro, "Small temperature benefits provided by realistic afforestation efforts," Nature Geoscience, vol. 4, no. 8, pp. 514-518, 2011.

[16] L. X. Chen Yuqi, S. Yan, and Z. Wen, "Land use changes caused by biofuel production," Journal of Natural Resources, vol. 25, no. 9, p. 10, 2010.

[17] A. Müller, J. Schmidhuber, J. Hoogeveen, and P. Steduto, "Some insights in the effect of growing bio-energy demand on global food security and natural resources," Water Policy, vol. 10, no. 1, pp. 83-94, 2008.

[18] X. Deng, J. Huang, E. Uchida, S. Rozelle, and J. Gibson, "Pressure cookers or pressure valves: do roads lead to deforestation in China?" Journal of Environmental Economics and Management, vol. 61, no. 1, pp. 79-94, 2011.

[19] G. B. Partnership, “The Global Bioenergy Partnership Sustainability Indicators for Bioenergy," 2011.

[20] M. D. A. Rounsevell, F. Ewert, I. Reginster, R. Leemans, and T. R. Carter, "Future scenarios of European agricultural land useII. Projecting changes in cropland and grassland," Agriculture, Ecosystems and Environment, vol. 107, no. 2-3, pp. 117-135, 2005.

[21] F. Hellmann and P. H. Verburg, "Spatially explicit modelling of biofuel crops in Europe," Biomass and Bioenergy, vol. 35, no. 6, pp. 2411-2424, 2011.

[22] D. B. Lobell, G. Bala, and P. B. Duffy, "Biogeophysical impacts of cropland management changes on climate," Geophysical Research Letters, vol. 33, no. 6, Article ID L06708, 2006.

[23] R. A. Betts, P. D. Falloon, K. K. Goldewijk, and N. Ramankutty, "Biogeophysical effects of land use on climate: model simulations of radiative forcing and large-scale temperature change," Agricultural and Forest Meteorology, vol. 142, no. 2-4, pp. 216233, 2007.

[24] R. A. Betts, "Biogeophysical impacts of land use on presentday climate: near-surface temperature change and radiative forcing," Atmospheric Science Letters, vol. 2, no. 1-4, pp. 1-13, 2001.

[25] R. A. Pielke Sr., J. Adegoke, A. Beltrán-Przekurat et al., "An overview of regional land-use and land-cover impacts on rainfall," Tellus, vol. 59, no. 3, pp. 587-601, 2007.

[26] R. A. Pielke Sr., G. Marland, R. A. Betts et al., "The influence of land-use change and landscape dynamics on the climate system: relevance to climate-change policy beyond the radiative effect of greenhouse gases," Philosophical Transactions of the Royal Society A, vol. 360, no. 1797, pp. 1705-1719, 2002.

[27] J. Feddema, K. Oleson, G. Bonan et al., "A comparison of a GCM response to historical anthropogenic land cover change and model sensitivity to uncertainty in present-day land cover representations," Climate Dynamics, vol. 25, no. 6, pp. 581-609, 2005.
[28] M. Beniston, D. B. Stephenson, O. B. Christensen et al., "Future extreme events in European climate: an exploration of regional climate model projections," Climatic Change, vol. 81, no. 1, pp. 71-95, 2007.

[29] K. Helming, K. Tscherning, B. König et al., "Ex ante impact assessment of land use changes in European regions-the SENSOR approach," in Sustainability Impact Assessment of Land Use Changes, pp. 77-105, Springer, 2008.

[30] J. J. Feddema, K. W. Oleson, G. B. Bonan et al., "Atmospheric science: the importance of land-cover change in simulating future climates," Science, vol. 310, no. 5754, pp. 1674-1678, 2005.

[31] R. D. Sands and M. Leimbach, "Modeling agriculture and land use in an integrated assessment framework," Climatic Change, vol. 56, no. 1-2, pp. 185-210, 2003.

[32] X. Deng, H. Su, and J. Zhan, "Integration of multiple data sources to simulate the dynamics of land systems," Sensors, vol. 8, no. 2, pp. 620-634, 2008.

[33] X. Deng, Q. Jiang, J. Zhan, S. He, and Y. Lin, "Simulation on the dynamics of forest area changes in Northeast China," Journal of Geographical Sciences, vol. 20, no. 4, pp. 495-509, 2010.

[34] J. Jin, N. L. Miller, and N. Schlegel, "Sensitivity study of four land surface schemes in the WRF model," Advances in Meteorology, vol. 2010, Article ID 167436, 11 pages, 2010.

[35] A. M. G. Klein Tank, J. B. Wijngaard, G. P. Können et al., "Daily dataset of 20th-century surface air temperature and precipitation series for the European Climate Assessment," International Journal of Climatology, vol. 22, no. 12, pp. 1441$1453,2002$.

[36] M. R. L. V. Leal, L. A. Horta Nogueira, and L. A. B. Cortez, "Land demand for ethanol production," Applied Energy, vol. 102, pp. 266-271, 2013.

[37] G. Sorda, M. Banse, and C. Kemfert, "An overview of biofuel policies across the world," Energy Policy, vol. 38, no. 11, pp. 69776988, 2010.

[38] D. Khatiwada, J. Seabra, S. Silveira, and A. Walter, "Accounting greenhouse gas emissions in the lifecycle of Brazilian sugarcane bioethanol: methodological references in European and American regulations," Energy Policy, vol. 47, pp. 384-397, 2012.

[39] A. P. C. Faaij, "Bio-energy in Europe: changing technology choices," Energy Policy, vol. 34, no. 3, pp. 322-342, 2006.

[40] I. I. Watkinson, A. V. Bridgwater, and C. Luxmore, "Advanced education and training in bioenergy in Europe," Biomass and Bioenergy, vol. 38, pp. 128-143, 2012.

[41] T. S. Buchholz, T. A. Volk, and V. A. Luzadis, "A participatory systems approach to modeling social, economic, and ecological components of bioenergy," Energy Policy, vol. 35, no. 12, pp. 6084-6094, 2007. 

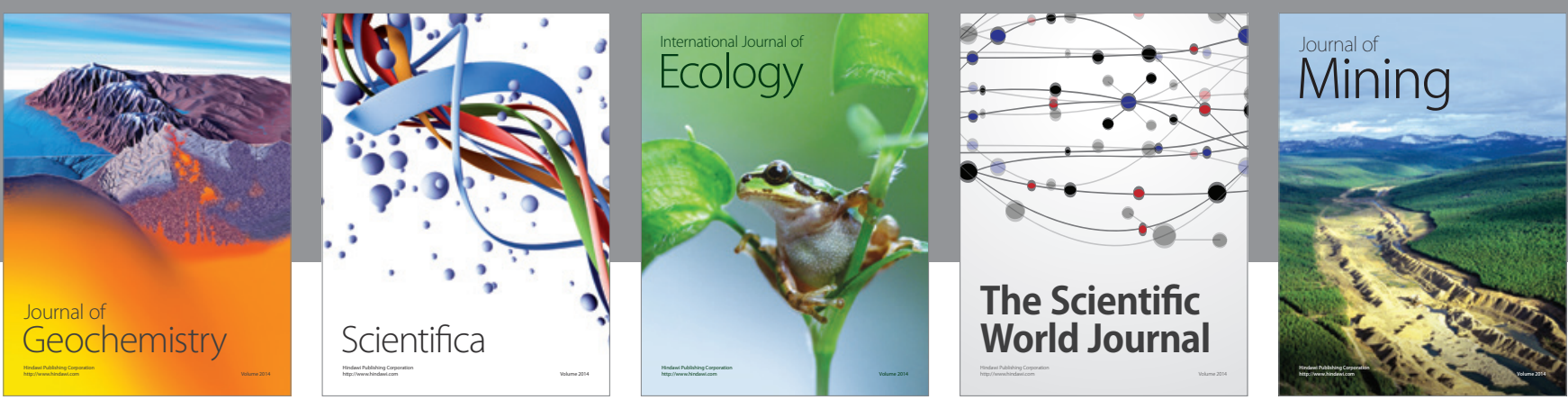

The Scientific World Journal
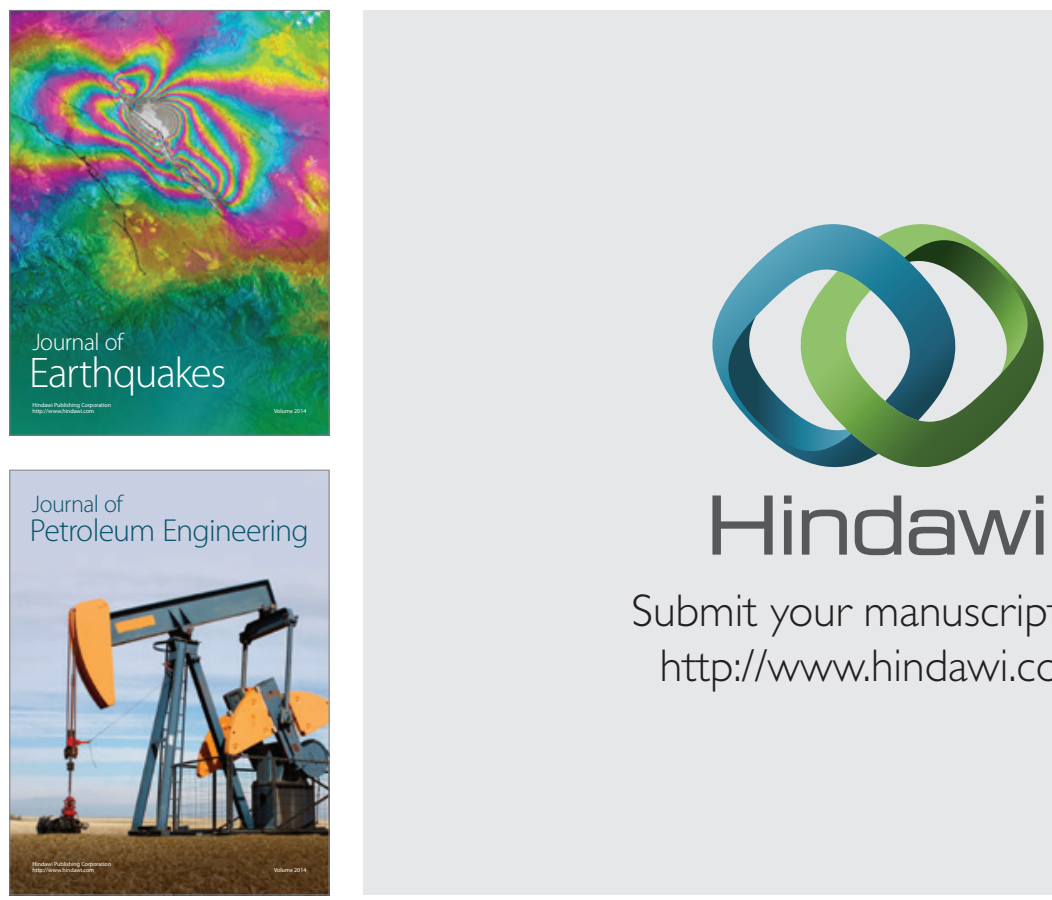

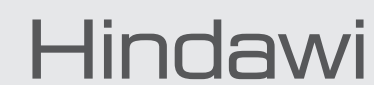

Submit your manuscripts at

http://www.hindawi.com
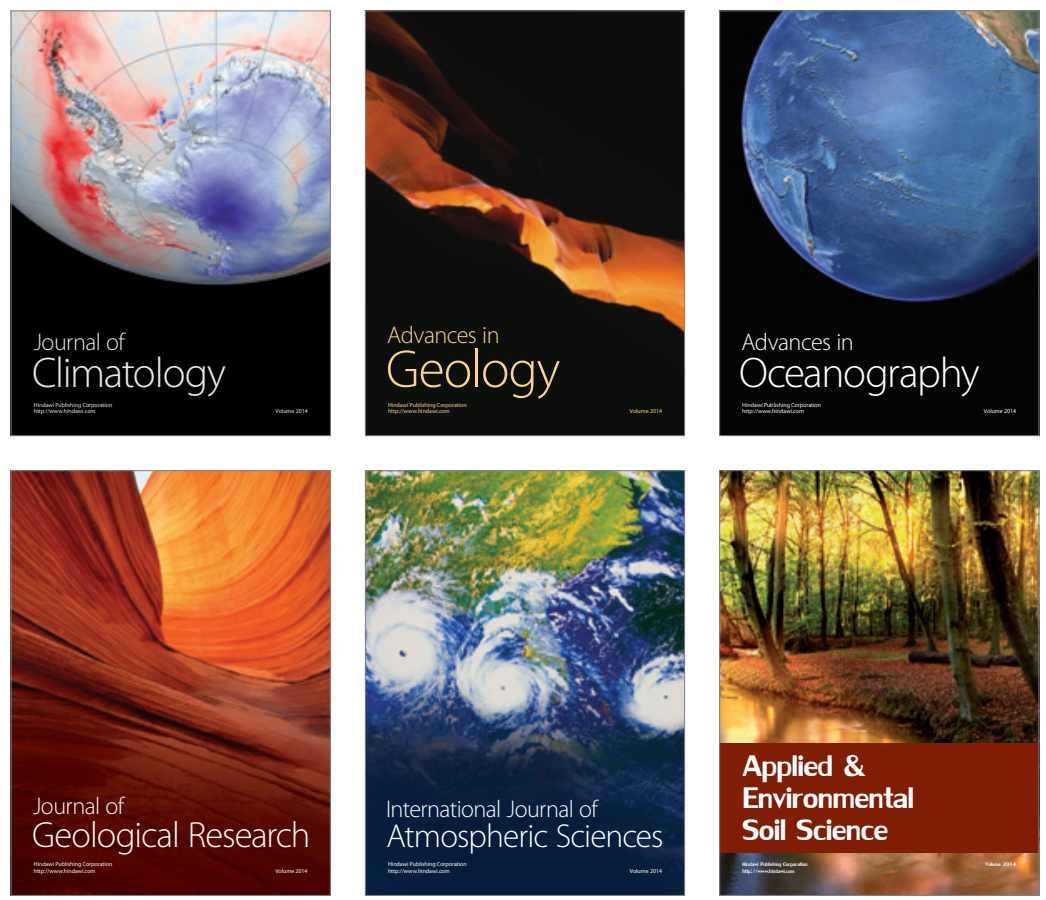
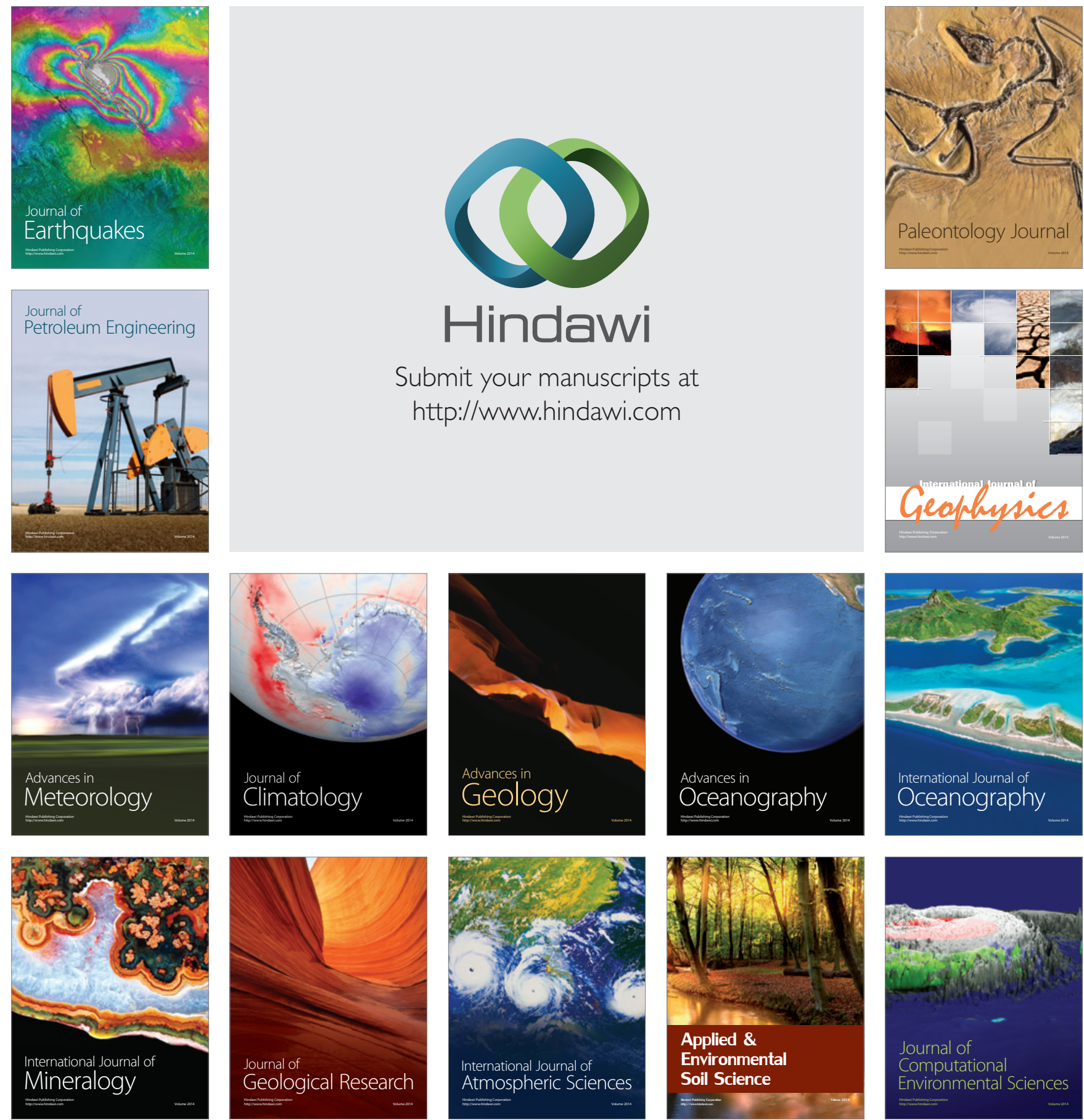